Base Renort

\title{
Rise of Online Advertising in India: An Overview
}

\section{Pallavi Mishra*}

University of Lucknow, 8/317 Vikas Nagar, Lucknow, Uttar Pradesh, India

\begin{abstract}
Online advertising, synonymous to Internet Advertising is defined as the paid form of promotion of ideas, goods and services to targeted Consumers using Internet. Online advertising is a comparatively nascent phenomenon for Indian advertising industry but has shown immense potential in its early years and is envisaged to give all other advertising mediums a run for their money in the near future. Internet has pervaded into almost every sphere of human life in past few decades. Businesses across the globe have already begun to realize its immense potential as a tool of commercial communication and profit maximization. One of the most conspicuous effects of internet in the business arena is discernible in the field of advertising. A whole new domain of advertising with revolutionary attributes and ramifications has evolved. Internet has inculcated various new and exciting dimensions to advertising providing advertisers with tools to capture attention of target audiences with greater accuracy and efficacy. The most important dimension that internet has added to advertising is that of 'measurability'. That is, the feedback to any advertising campaign on internet can be measured fairly accurately, rendering it possible for advertisers to ascertain productivity of their investment in the campaign objectively. One of the main advantages of internet advertising is the ability to publish information instantaneously with the convenience of modifying the content according to requirements without bothering about constraints of time and geography. This paper dives into the online advertising market in India closely tracking the way in which the Indian online ad Industry has evolved.
\end{abstract}

\section{Methodology}

AI propose to employ Library Research and Online Research methods of data collection for exploring the dimensions of Online Advertising.

\section{Introduction}

Online advertising may be defined as promoting goods, ideas or services to targeted consumers using internet as medium. Internet has inculcated various new and exciting dimensions to advertising providing advertisers with tools to capture attention of target audiences with greater accuracy and efficacy. The most important dimension that internet has added to advertising is that of 'measurability'. That is, the feedback to any advertising campaign on internet can be measured fairly accurately, rendering it possible for advertisers to ascertain productivity of their investment in the campaign objectively. One of the main advantages of internet advertising is the ability to publish information instantaneously with the convenience of modifying the content according to requirements without bothering about constraints of time and geography [1]. Online advertising is highly apposite for 'consumer-segmentation', a process that helps in creating well defined consumer groups making it easier for advertisers to create specially designed messages for specific consumer-segments. There are immense opportunities in the field of internet advertising for advertisers but there are plenteous obstacles as well that need to be eradicated before full potential of internet advertising can be realized. The potential of internet advertising can be gauged by the fact that internet advertising revenues in the United States alone totalled $\$ 12.1$ billion for the first six months of 2010 [2]. This is indicative of the growth potential this industry has in store for developing countries like India.

\section{Forms of online advertising}

The Internet is a great place to advertise. There are many forms of online advertising. Some of the main ones involved:

\footnotetext{
* E-mail sponsorship advertising

* Newsletter and E-zine advertising
}

* Rich media advertising (flash ads, Interstitials \& Superstitials, streaming audio/video, etc)

$$
\begin{aligned}
& \text { * Pop-up/pop-under advertising } \\
& \text { * Online banner advertising } \\
& \text { * Sponsorship (web sites, e-mails, sweep stakes) } \\
& \text { * Advertorial (Paid-for editorial) placements }
\end{aligned}
$$

\section{Online advertising: Indian perspectives}

Online advertising is still in the embryonic stages in India, while in other parts of the world it has already taken deep roots. The share of India's online advertising in world pie is almost negligible. But developing countries like India; where Internet users are growing very rapidly, it has huge potential. India's leading advertisers are starting to advertise online, but at a very slow pace. Indian companies are also showing keen interest in promoting their products or services online. Currently finance sector is most dominating sector in online advertising and accounted about $40 \%$ of total online advertising in India. Some of the leading companies from this sector are HDFC, Citibank, SBI, and UTI etc. FMCG goods have just started to come in led by companies like Hindustan Lever, Procter and Gamble etc. India is among the fastest growing economies of the world. Economic Survey of India has predicted that Indian Gross Domestic Product (GDP) will grow at a rate of $6 \%$ in the financial year 2013-14. The growth that has occurred

*Corresponding author: Pallavi Mishra, University of Lucknow, 8/317 Vikas Nagar, Lucknow, Uttar Pradesh, India, Tel: 9451951319; E-mail: pallavimishra34@gmail.com

Received November 26, 2013; Accepted December 27, 2013; Published January 01,2014

Citation: Mishra P (2014) Rise of Online Advertising in India: An Overview. J Mass Communicat Journalism 4: 172. doi:10.4172/2165-7912.1000172

Copyright: (c) 2014 Mishra P. This is an open-access article distributed under the terms of the Creative Commons Attribution License, which permits unrestricted use, distribution, and reproduction in any medium, provided the original author and source are credited. 
in India since the adoption of Industrial Policy of 1991 coupled with the recent economic recession in the developed western countries has made India one of the most sought after business destinations in the world. Also, a large population with continuously increasing purchasing power has resulted in creation of a stupendously huge and lucrative market. This augurs well for Indian Advertising Industry which is now looking at harnessing the benefits of internet to augment its growth [3-5]. Total Online Advertising market of India was estimated at INR 785 crores for the financial year 2009-10 and is estimated to grow in the coming financial year. This amounts to a remarkable increase of approximately $26 \%$ over the previous financial year. Display advertisements constitute a major portion of this revenue generation followed by text advertisements. Display advertisements contributed about INR 417 crores, whereas text advertisements about INR 368 crores, in the total revenues generated by the industry during the financial year 2009-10. Display advertisements are expected to post a growth of 30\% in the financial year 2013-14 followed closely by text advertisements which are expected to grow at $26 \%$ during the same period. Still the size of internet advertising industry in India is miniscule when compared to developed western countries. Online advertising is among the most extensively talked about topic in the world of advertising. In Developed countries, online advertising has already become a big phenomenon and is attracting both the advertisers as well as the consumers owing to its plethora of advantages over traditional forms of advertising. Rupert Murdoch has famously said, "The Internet has been the most fundamental change during my lifetime and for hundreds of years." This statement coming from arguably the most influential persons of our time epitomises the importance in the world of communication and media. Internet has changed the rules of the entire communication game. Online is the only place where the world wants to be and advertisers are no exception [6]. The increasing predilection of the advertisers towards is not because of a rat-race, but due to multifarious advantages it provides over other forms of advertising. David Meerman Scott, Eminent Marketing Guru and famous speaker once said, "You can buy attention (advertising). You can beg for attention from the media (PR). You can bug people one at a time to get attention (sales). Or you can earn attention by creating something interesting and valuable and then publishing it online for free." David Meerman Scott, Eminent Marketing Guru and famous speaker. The claim about online advertising being completely free may be a little exaggerated; nevertheless, the cost-effectiveness of online advertising cannot be challenged. Online advertising methods are, arguably, leading to significant reductions in transactions costs between merchants and consumers. The methods enable merchants to deliver information that is targeted to those consumers who value the information the most and are most likely to act on it. David Evans in his research paper "The Online Advertising Industry: Economics, Evolution and Privacy" has mentioned that Online advertising accounts for almost 9 percent of all advertising in the United States. Online advertising started in United States in 1994 when Hot Wired, a web magazine, sold a banner ad to AT\&T and displayed it on their web page [7]. Origin of online advertising is a disputed topic amongst the scholars. Still, there is considerable research going on the topic in the developed countries like United States, but in India amount of research on advertising is exiguous. In India, there is little data available regarding the genesis and development of online advertising and there is almost no research being carried out regarding its future prospects at present [8]. Although few industry specific studies are there, but there is no authentic academic research available in the area in our country. Even in the context of the world, research in the field of online advertising started as late as towards the end of the twentieth century. Berthon, Pitt and Watson's article on online advertising published in the
Journal of Advertising Research is considered to be the first authentic research study in the field. In India, however, there is severe dearth of authentic scholarly articles on the topic [9].

There are various dimensions of Online Advertising that need to be explored and deliberated upon by the researchers and industry experts before it can be catapulted into the high growth orbit [10-15]. Online advertising is already a booming industry in the developed countries with companies like Google and Yahoo making billions out of it. However, in India there is still scepticism about the utility of online advertising as a potent tool of Integrated Marketing Communications capable of reaching the masses and more importantly, increasing revenues and augmenting profits. John Wanamaker, who may be regarded as the first advertiser of the world, has famously said during the later decades of the nineteenth century that, "Half the money I spend on advertising is wasted. The trouble is, I don't know which half [16]." Now in the beginning of the twenty-first century, Greg Stuart, chief of Internet Advertising Bureau, United States of America, estimates that 'advertiser's waste'- the advertising messages that do not reach the targeted audiences or advertising messages received by none at all - is around \$112 million in America alone and \$220 million in the world, amounting to half of the total expenditure of the advertisers. This is the biggest drawback of traditional advertising. Online advertising, which adopts a completely different model of advertising, is in a position to minimize this humungous waste which costs advertisers very dearly. Traditional advertising is directed towards theoretical audiences who may or may not be receiving and responding to advertising messages as planned or perceived by the advertisers, leading to wastage of exorbitant amounts of money and labor. Internet advertising can be used effectively to minimize advertiser's waste, reduce per capita cost of advertising, ensure that the advertising messages reach to their target audiences and authentic feedback is received. The opportunities in the field of online advertising are innumerable, but to reap the benefits of online advertising, Indian companies and businesses need authentic data regarding the behavior of the consumers, various latent attributes of online advertising, the manner in which it impacts the prospective leads or turns casual bystanders into leads and the factors impeding its growth are required. There is negligible research in the field of online advertising in India. This research study will endeavour to provide authentic data regarding the genesis and growth of online advertising in India and will aim to delineate various routes that online advertisers may take to maximize their benefits on every rupee spend on advertising [17]. This will also pave way for further research in the field and provide a foundation on which new edicts will be raised.

\section{Internet and online advertising}

The Internet has produced a revolutionary new way for business to communicate and interact with customers. Everyone from small businesses to fortune 500 companies are racing to make their mark in cyberspace with their own "Home Pages" on the world wide web (www). The reason it presents great advertising opportunities for marketers because of its continuing growth [18]. The number of Internet users around the world is constantly growing. The computer industry almanac has reported that by the year 2005, 118 people per 1000 around the world will have Internet access. As Internet users are growing day by day; so are Internet advertisers because they can easily, effectively and efficiently communicate their products or services to targeted mass audience. Add to this the fact that Internet users are well educated with high incomes, it is only logical to conclude that Internet surfers are a desired target for advertisers. 


\section{Reasons for the growth of online advertising in India}

* Advertisement can reach very large number of potential buyers globally.

* Web superiority over other advertising medium.

* Web page (advertisement) can be updated any time and changes or corrections are painless.

* Online advertisement works 24 hours a day, 7 days a week, 365 days a year.

* In online advertisement specific interest groups or individuals can be targeted.

* Online advertisement can effectively use the convergence of text, audio, graphics, and Animation.

* Online advertisements are cheaper in comparison to traditional advertisement. There is no printing costs, no postage costs etc.

\section{Benefits of online advertising}

The Internet has great potential as media carrier compared to traditional media. It offers higher selectivity which is tailored to the user's profile. The customer can also customize the adverts as he/she is in charge of his own navigation [19-21]. Through the online advertising the advertiser can get quick, easy and inexpensive feedback in real time, which no other media offers, providing a higher feedback rate. Some other benefits of online advertising are as under:

* Online advertising facilitates the advertiser to reach an absolutely pinpointed and targeted audience.

* "Traditional advertising is usually a one-way mechanism there is no way for customers to act on the information in the advertisements. On the Internet, however, interested customers can click on a banner, learn more, and actually make purchase on the spot,"

* The Internet as a medium knows no demographic boundaries and gives the advertiser a huge audience to tap and build brand image if not sell products.

* Internet's interactive nature allows for greater flexibility than traditional media in the type of information transmitted and the method of transmission.

* Online advertisement can facilitate purchase decision.

* Enhance customer company relationship.

* Protection of environment.

* Online advertisement expands the company's market to global market.

* It is easy to create, and place, it saves time, labor and money.

* No loss of quality even after a very long period of time.

\section{Conclusion}

No doubt, online advertising offers potential benefits like target ability, tracking, deliverability, flexibility, interactivity, so it is in its developing phase in India. The fact in favour of India is that most of the western developed economies have become saturated with negligible growth potential while India has vast untapped markets and enormous growth potential. Now to exploit the vast potential of internet advertising in India it is imperative that comprehensive policies are made to facilitate growth of the industry and business conglomerates should foray into the unknown territories of the industry in order to support its growth and development. This is not an easy task given the complex demographic variables like socio-cultural, linguistic and religious diversity of India, highly skewed per capita income, urbanrural divide, etc. There are numerous lacunae that need to be filled before internet advertising industry can flourish in India.

\section{References}

1. http://fuelingnewbusiness.com

2. http://www.intertic.org

3. http://www.ccaoi.in/Ul/links/fwresearch/Research\%203rd\%20July.pdf

4. http://adclubtoledo.org/wp-content/uploads/2010/02/jcira.spring2008 onlinereview.pdf

5. http://books.google.co.in/books?id=G4fves4jOuMC\&pg=PA45\&dq=online+ad ertising+in+ln dia\&hl=en\&sa=X\&ei=pXyT7OhBa3MmAXqhYWdBQ\&ved=0CF $M Q 6 A E w A Q \# v=o n e p a g e \& q \& f=$ false

6. Gupta, Om (2005) Advertising in India: Trends and Impact. Gyan Publishing House.

7. Promises of E-governance-Operational Challenges' a compilation of research papers published by Power Grid Corporation of India Limited.

8. International Telecommunication Union (ITU) website.

9. 'Digital India - A Call for Action' published by Internet and Mobile Association of India (IAMAI) in 2009.

10. http://www.internetworldstats.com

11. http://www.iamai.in

12. http://www.ispai.in/broadband.html

13. The Times of India.

14. Draft Strategy Plan, Department of Information Technology Ministry of Information and Broadcasting.

15. http://www.iab.net

16. Internet for Rural India (2009) A report published by Internet and Mobile Association of India.

17. New Delhi, March 03, 2010.

18. http://www.economist.com

19. Internet Advertisements (2010) A report published by Internet and Mobile Association of India.

20. Report on Vernacular Content (2009) published by Internet and Mobile Association of India.

21. http://businesstoday.intoday.in/bt 